\title{
Alcohol-related harm: perceptions of ambulance officers and health promotion actions they do and would do
}

\author{
Marita Lynagh, Rob Sanson-Fisher and Anthony Shakeshaft
}

\section{Introduction}

The misuse of alcohol and associated harms is a major international social and public health problem, responsible for 2.3 million premature deaths worldwide and $4.4 \%$ of the global burden of disease. ${ }^{1}$ Alcohol is implicated in $26 \%$ of road fatalities, ${ }^{2}$ in two out of every five divorces or family separations and violent crimes in Australia, and is associated with obesity, high blood pressure, domestic violence and other injuries. ${ }^{3}$ The global economic cost is immense, estimated to be between US\$210,000 and US\$665,000 million. ${ }^{1}$ Growing recognition of the enormous burden imposed by alcohol and alcohol-related harms has led to national policies and initiatives in a number of countries and there are indications that the World Health Organization is soon to embark on a global offensive. ${ }^{4}$

Reduction in risky drinking and associated harms are priority goals of governments and health agencies across nations.
Health care providers have a vital role to play in contributing to appropriate and effective strategies in a number of areas. In Australia, the 2005 - 2009 National Alcohol Strategy recommends broadening the provision of screening and brief alcohol interventions in primary and acute care settings. Providing encouragement and support for health care providers to implement early alcohol interventions, and exploring opportunities for community-based action are also identified as prospective areas for investigation. ${ }^{5}$ Research on the role of health care providers in delivering alcohol screening and interventions to-date has largely focused on general practitioners (GPs), with studies demonstrating that GPs can be effective in reducing excessive alcohol consumption. ${ }^{6-8}$ Much less attention has been given to the potential role of other health care providers, with the exception of recent investigations into the role of staff in Emergency Departments (EDs) in hospitals. ${ }^{9,10}$ One group of health care providers who

\section{Abstract}

Issue addressed: Health care providers play a pivotal role in preventing and reducing the burden associated with the misuse of alcohol, yet one group whose role in the alcohol offensive has not yet been systematically explored is ambulance officers. This study attempted to firstly, measure the prevalence and type of alcoholrelated incidents attended by ambulance officers, and secondly, identify both current practice and perceived role in reducing alcohol-related harms.

Methods: A cross-sectional, descriptive survey of 264 NSW Ambulance Officers was conducted in June and July 2006.

Results: Results indicated that alcohol plays a significant role in the work of ambulance officers with estimates of $20 \%$ of all call-outs involving alcohol. Though the majority of officers indicated that they usually or always asked patients whether they have been drinking, far fewer asked about quantity and frequency of alcohol use and only small proportions undertook formal screenings, offered brief advice or referred patients to an appropriate drug and alcohol service.

Conclusion: Officers indicated that they are willing to undertake a number of other actions as part of alcoholharm reduction efforts, suggesting that many ambulance officers consider health promotion to be integral to the role of an ambulance officer.

Key words: alcohol, ambulance, harm reduction.

Health Promotion Journal of Australia 2010; 21:19-25

\section{So What}

Ambulance officers are ideally suited to identify and detect 'at-risk' drinkers and there are a number of unrealised opportunities for expansion of the health promotion role, which they appear willing to undertake. 
are in a potentially pivotal position to detect and intervene with patients who engage in risky alcohol consumption, but whose role has not yet been systematically explored, is ambulance officers.

Research has shown that excessive drinkers are overrepresented in EDs with estimates of between 2\% and 40\% of ED presentations being alcohol-related, ${ }^{11}$ many of whom have been transported by ambulance. Ambulance officers also attend and treat many patients who are not transported to hospital or come into contact with other health services. ${ }^{12}$ Alcohol and alcohol-related harm plays an increasingly significant role in the work of ambulance and emergency service personnel. For example, data from a single ambulance station in New South Wales indicated that $14 \%$ of all call-outs involved alcohol, with patients in more than half of these showing signs of moderate to high levels of intoxication. ${ }^{13}$ In the later half of 2007, alcohol was responsible for $39 \%$ of all drug-related deaths attended by ambulance staff in metropolitan Melbourne, an increase of $30 \%$ from the same period in the previous year. ${ }^{14}$ In the UK, the London Ambulance Service noted that 6\%, or 61,000 incidents a year, attended by ambulance officers are alcohol-related, which increases to $15 \%$ on Friday and Saturday evenings. ${ }^{15}$

Ambulance officers view first hand the environment in which people live, work and recreate, and are therefore in a unique position to record and integrate this information in to a model of practice. ${ }^{16,17}$ They can detect public health issues that are prominent or on the increase in the communities in which they work, and can identify individuals at risk for early referral to appropriate services. ${ }^{17}$ This may be especially important in rural communities where a limited number of GPs and often no drug and alcohol services are available. Ambulance officers are then an important point of contact with the atrisk population of drinkers, and hold a number of unrealised opportunities to participate in alcohol misuse data collection and harm reduction interventions. These include: first, at the site of the incident and/or at the time of delivering emergency care; second, during the period of transportation to hospital; third, through follow-up of patients by mail or telephone contact post-incident; and fourth, involvement in other primary prevention initiatives, such as community education, advocacy and networking with other health care providers.

Recent state and national symposia ${ }^{18}$ support broadening the scope of ambulance services and reviewing data collection schemes. Yet to date, little, if any, research has explored the potential insights that ambulance data may afford in relation to alcohol-related harm. Further, no studies have explored the relevant knowledge and current practices of ambulance officers when caring for alcohol-affected patients, nor their perceptions regarding their role as health care providers.
This research is the first of its kind that aimed to estimate the prevalence and type of incidents attended by ambulance officers where alcohol is involved. As not all Australian states and territories currently use electronic Patient Care Records (PCRs) and paper-based PCRS do not allow for the recording of detailed information on alcohol-related incidents, a quantitative audit of PCRs was not viable. Evidence ${ }^{13}$ also suggests that paper-based PCRs are not always completed for all patients, particularly for those who are not transported or refuse treatment and/or are uncooperative, resulting in inaccurate databases. Therefore, this study measured the prevalence and type of incidents as perceived by ambulance officers. Additional aims of the study were to identify levels of knowledge and practice among officers in regard to caring for patients perceived to be affected by alcohol, and to explore officers' perceived role in caring for alcohol-affected patients and in reducing alcohol-related harm.

\section{Methods}

\section{Study design}

A cross-sectional, descriptive survey of NSW Ambulance Officers was conducted in June and July 2006.

\section{Respondents and sampling}

At the time of the survey, approximately 2,626 personnel were employed as officers with the Ambulance Service of New South Wales (ASNSW). A stratified random sample of 500 ambulance officers from all four sectors across NSW were selected and invited to participate in the study. All ASNSW staff who had been working as an officer in NSW for a period of six months or longer were eligible for inclusion. The sample of officers selected to participate was in proportion to the total population of officers by the four main divisions or area sectors in NSW.

\section{Survey measures}

A self-administered eight-page pen-and-paper questionnaire was developed in consultation with researchers and ambulance officers and then piloted with a small number of volunteer ambulance officers. The questionnaire was pre-coded for data entry with many items using a 5-point Likert scale response option, and contained the following sections: ambulance officer demographics; training in alcohol; perceived estimates of incidents involving alcohol; types of incidents in which alcohol is likely to be involved; current practices in regard to caring for patients affected by alcohol; perceived confidence in caring for patients affected by alcohol; perceived role as health care providers; and specific alcohol interventions willing to deliver. An optional openended item also allowed participants to provide any general 
comments in regard to alcohol and/or their role in caring of alcohol-affected patients.

A letter of invitation and a copy of the questionnaire together with a reply-paid self-addressed envelope were sent to selected ambulance officers at their work stations through the ASNSW internal mail system. Two reminder letters and additional surveys were also sent out at two weeks and five weeks after the initial mail-out to maximise the response rate.

\section{Analysis}

Data were analysed using SAS software (version 8.2). After data entry was complete, means and standard deviations were calculated for continuous variables and proportions and 95\% confidence intervals reported for categorical variables.

\section{Results}

\section{Sample characteristics}

A total of 264 officers (out of 500) participated in the study, providing a response rate of $53 \%$. This sample size provided estimations of findings with a 95\% confidence interval to a precision within $\pm 6 \%$ for proportions and dichotomous variables and with \pm 0.12 of a standard deviation for continuous variables. Table 1 shows the demographic characteristics of the study sample. There were more males than females, reflecting the higher proportion of male ambulance officers in the workforce, with most participants aged between 31 and 50 years. Participants had an average

Table 1: Demographic characteristics of study sample.

\begin{tabular}{|c|c|c|}
\hline & $\mathbf{N}$ & $\%$ \\
\hline \multicolumn{3}{|l|}{ Gender } \\
\hline Male & 192 & 73 \\
\hline Female & 72 & 27 \\
\hline \multicolumn{3}{|l|}{ Age } \\
\hline $20-30$ yrs & 45 & 17.5 \\
\hline $31-40$ yrs & 98 & 38 \\
\hline $41-50$ yrs & 80 & 31 \\
\hline$>50$ yrs & 35 & 13.5 \\
\hline \multicolumn{3}{|c|}{ Position classification } \\
\hline Level 1-2 & 42 & 16 \\
\hline Level 3-4 & 147 & 57 \\
\hline Level 5 & 48 & 19 \\
\hline Other & 22 & 8 \\
\hline \multicolumn{3}{|c|}{ Years working in ASNSW } \\
\hline $0-5$ yrs & 89 & 34 \\
\hline $6-10$ yrs & 49 & 19 \\
\hline $11-20$ yrs & 59 & 23 \\
\hline$>20 \mathrm{yrs}$ & 62 & 24 \\
\hline Division Sector & NSW & Sample \\
\hline Northern & $27 \%$ & $29 \%$ \\
\hline Southern & $17 \%$ & $16 \%$ \\
\hline Sydney & $42 \%$ & $44 \%$ \\
\hline Western & $13 \%$ & $11 \%$ \\
\hline
\end{tabular}

of 13 years experience working as an ambulance officer, with a range of one to 44 years.

\section{Prevalence estimates of alcohol-related call-outs}

Excluding pre-booked patient transportation or inter-hospital transfers, $54 \%$ of officers estimated that at least $20 \%$ or higher of all call-outs or incidents they attended involved patients who are affected by alcohol. Twenty per cent of officers estimated that the rate was as high as $40 \%$ or more. When focusing on the hours of 10 pm to 6 am, estimates of alcohol-related call-outs rose to $30 \%$ or higher, with $27 \%$ of officers estimating rates as high as $50 \%$ or more. When asked to estimate the proportion of all call-outs involving alcohol-affected patients who were not transported to an ED or other health service, $46 \%$ of officers estimated this figure to be around 1 in 5 or higher. In regard to the types of incidents that they typically attend, the majority of officers estimated that eight out of every 10 incidents of domestic violence (61\% of officers) and assault (71\% of officers), five out of every 10 incidents of suicide or attempted suicide (63\% of officers), and four out of every 10 MVAs attended (43\% of officers) involved patients affected by alcohol.

\section{Current practice and level of confidence}

When asked about current clinical practice in regard to caring for patients affected by alcohol, the majority of officers (66\%) reported that they either 'usually' or 'always' ask patients whether they have been drinking, document their intervention and treatment (95\%), and to a lesser extent ask about the quantity and frequency of use of alcohol (40\%). Far fewer officers reported consistently discussing with or advising patients to change their drinking behaviour (4\%), screening patients for alcohol problems using a formal screening tool (1\%) or referring patients to an appropriate Drug and Alcohol (D\&A) service (4\%) (see Table 2). Most officers (95\%) reported a 'moderate' or 'high' degree of confidence in: being able to ask patients if they had been drinking; questioning patients about the quantity and frequency of alcohol use (84\%), and; documenting their care on the PHC Records (78\%). Fewer proportions of officers were confident in discussing with or advising patients to change their drinking behaviour (34\%), screening patients for alcohol problems (12\%) and referring patients to appropriate D\&A service (32\%).

\section{Training on alcohol}

Though nearly half of all officers (48\%) reported receiving between one and 10 hours of training devoted to alcohol as part of their initial ambulance officer training, almost the same proportion (43\%) reported having received no training at all as shown in Figure 1. In regards to the past year, $85 \%$ of officers indicated they had had none and $13 \%$ had attended between one and two hours of formal training sessions on alcohol. 


\section{Attitudes and beliefs about alcohol}

There was strong agreement among officers (93\%) that alcohol is a major social and public health problem and most (75\%) disagreed that illicit drugs were a bigger problem in Australia, as shown in Table 3. A large number of officers (79\%) agreed that dealing with alcohol-affected patients is a significant part of their work and supported the need (94\%) to receive training on how to deal with patients affected by alcohol. A significant proportion (70\%) agreed that officers should also receive training on how to make referrals and provide brief alcohol advice. Forty-four per cent of officers believed that it takes too much time to deal with individual patient's drinking behaviour and $46 \%$ thought that patients would get angry if questioned about their drinking. Forty-six per cent believed that there are not enough places currently available to refer patients for alcohol counselling, while $48 \%$ were unsure about the availability of services for referral.

\section{Perceived role and actions willing to undertake}

While there was total agreement (100\%) among participants that the main roles and responsibilities of an ambulance officer are to provide emergency pre-hospital care and retrieve and transport patients, significant proportions of officers also believed that their role also included: identifying patients at risk and referring them to appropriate services (60\%); providing public health education and health promotion (56\%), and; participating in research (86\%) (see Table 4). In regard to actions specific to alcohol-reduction efforts, large proportions of officers indicated willingness to: ask patients about their alcohol use (98\%); refer patients to appropriate services (68\%), and; provide patients with written information

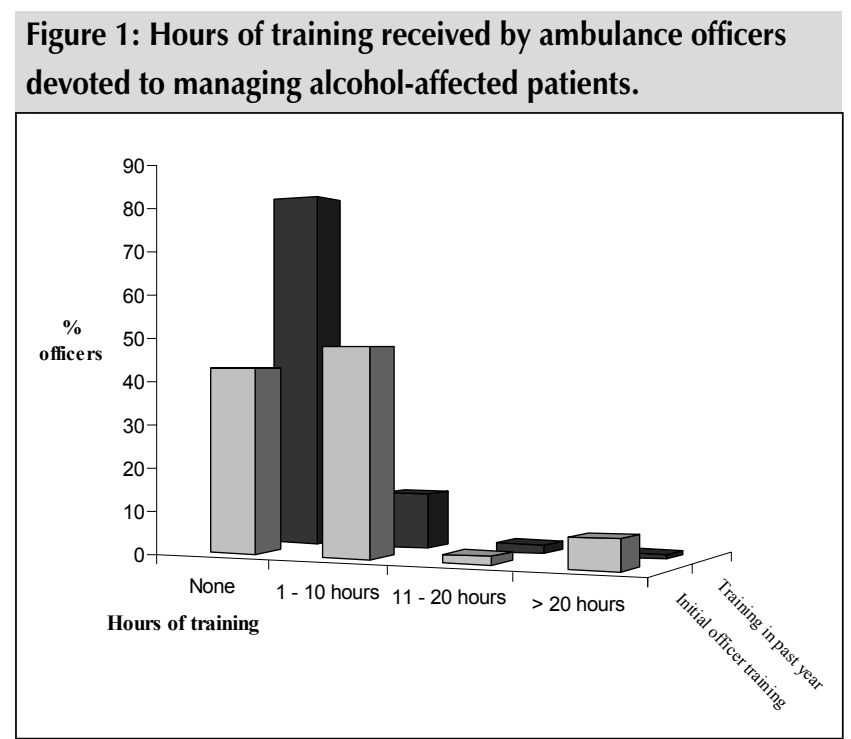

Table 2: Current practice and level of confidence in regard to caring for alcohol-affected patients.

\begin{tabular}{|c|c|c|c|c|c|c|}
\hline \multirow[b]{2}{*}{ Action } & \multicolumn{3}{|c|}{ Current Practice } & \multicolumn{3}{|c|}{ Level of Confidence } \\
\hline & Usually/Always & Some-times & Never/Rarely & Moderate/High & Medium & None/Low \\
\hline Ask patients whether they have been drinking & $66 \%$ & $31 \%$ & $3 \%$ & $95 \%$ & $4 \%$ & $1 \%$ \\
\hline Ask patients about their quantity and frequency of alcohol & $40 \%$ & $42 \%$ & $18 \%$ & $84 \%$ & $9 \%$ & $7 \%$ \\
\hline Screen patients for alcohol problems using a formal alcohol screening tool & $1 \%$ & $1 \%$ & $98 \%$ & $12 \%$ & $10 \%$ & $78 \%$ \\
\hline Discuss/advise patients to change their drinking behaviour & $4 \%$ & $24 \%$ & $72 \%$ & $34 \%$ & $25 \%$ & $41 \%$ \\
\hline $\begin{array}{l}\text { Refer patients with alcohol problems to an appropriate drug } \\
\text { and alcohol counselling service }\end{array}$ & $4 \%$ & $14 \%$ & $82 \%$ & $32 \%$ & $21 \%$ & $47 \%$ \\
\hline $\begin{array}{l}\text { Document assessment, intervention and/or referral on the } \\
\text { Patient Health Care Record }\end{array}$ & $95 \%$ & $4 \%$ & $1 \%$ & $78 \%$ & $13 \%$ & $9 \%$ \\
\hline
\end{tabular}

Table 3: Attitudes and beliefs towards alcohol and early alcohol intervention.

\begin{tabular}{|c|c|c|c|}
\hline & \multicolumn{3}{|c|}{ Level of Agreement } \\
\hline & $\begin{array}{l}\text { Agree/ } \\
\text { Strongly Agree }\end{array}$ & Unsure & $\begin{array}{l}\text { Disagree/ } \\
\text { Strongly Disagree }\end{array}$ \\
\hline Alcohol is a major social and public health problem in Australia. & $93 \%$ & $3 \%$ & $4 \%$ \\
\hline Illicit drugs are a bigger problem to the community than alcohol. & $13 \%$ & $12 \%$ & $75 \%$ \\
\hline Dealing with patients affected by alcohol is a significant part of my work. & $79 \%$ & $2 \%$ & $19 \%$ \\
\hline Ambulance officers see first hand the negative effects of alcohol abuse by people. & $96 \%$ & $2 \%$ & $2 \%$ \\
\hline It is appropriate that ambulance workers are given training in how to deal with alcohol-affected patients. & $94 \%$ & $2 \%$ & $4 \%$ \\
\hline $\begin{array}{l}\text { Talking to patients about their drinking behaviour is an important part of my responsibilities as an } \\
\text { ambulance officer. }\end{array}$ & $34 \%$ & $21 \%$ & $45 \%$ \\
\hline It takes too much time to deal with each individual patient's drinking behaviour. & $44 \%$ & $20 \%$ & $36 \%$ \\
\hline There are not enough places to refer patients for alcohol screening. & $46 \%$ & $48 \%$ & $6 \%$ \\
\hline Advising patients about their problem drinking behaviours may lead to early, successful intervention. & $45 \%$ & $34 \%$ & $21 \%$ \\
\hline Patients will be angry if I ask questions about their drinking behaviour. & $46 \%$ & $13 \%$ & $41 \%$ \\
\hline Alcohol treatment programs do not work. & $6 \%$ & $37 \%$ & $57 \%$ \\
\hline My involvement with a patient can make a difference regarding their alcohol use. & $28 \%$ & $40 \%$ & $32 \%$ \\
\hline $\begin{array}{l}\text { It is a waste of ambulance officers' time to try to prevent future alcohol-related harm by talking } \\
\text { to patients about their alcohol use. }\end{array}$ & $25 \%$ & $24 \%$ & $51 \%$ \\
\hline $\begin{array}{l}\text { It is appropriate that ambulance officers are given training in how to make referrals and give } \\
\text { brief alcohol counselling advice. }\end{array}$ & $70 \%$ & $11 \%$ & $19 \%$ \\
\hline
\end{tabular}


on alcohol and local services (74\%). Significant numbers also indicated a willingness to attend training programs (65\%), meet with local GPs and other health care workers to identify and plan more effective referral networks (64\%), deliver talks to community groups (52\%), and work with police and other agencies to develop harm reduction strategies (67\%).

\section{Discussion}

To better understand the potential role that ambulance services can play in contributing to efforts to reduce the significant harms associated with alcohol misuse, this study surveyed ambulance officers across New South Wales to identify current practices and perceptions of their role in caring for alcohol-affected patients. Consistent with other research findings, ${ }^{13}$ alcohol plays a significant role in the work of ambulance officers with estimates of call-outs involving alcohol ranging from $20 \%$ or higher of all call-outs to $30 \%$ or higher of call-outs between the hours of $10 \mathrm{pm}$ and $6 \mathrm{am}$. These were supported by strong beliefs among officers on the burden of illness associated with alcohol and a high level of agreement (79\%) with the considerable workload imposed by alcohol. This study did not make a distinction between weekdays and weekends, but it is likely that weekends involve higher rates of alcohol-related incidents. This is certainly the case in EDs, with studies showing that there are twice as many alcohol-related ED presentations on weekends compared to weekdays. ${ }^{9}$ There also appear to be clear patterns of association between alcohol and the types of incidents attended by officers with alcohol more likely to be involved in domestic violence, assault, suicide attempts and motor vehicle accidents. This is not a surprising finding given the very clear association between alcohol and adverse outcomes demonstrated in research conducted worldwide. ${ }^{3}$

The high estimated prevalence rates of alcohol-related callouts found in this study may indicate the true prevalence or they may reflect a perceived higher clinical burden associated with caring for and treating alcohol-affected patients. ${ }^{9}$ It is important to validate staff perceptions with direct measures based on patient records and ambulance data. Changes to the mechanisms for assessing and recording alcohol-related data by ambulance staff could potentially provide a more accurate and rich, unique data set on the prevalence and characteristics of alcohol-related harm in the community.

Though the majority of officers surveyed in this study indicated that they usually or always asked patients whether they have been drinking, far fewer (40\%) asked about quantity and frequency of alcohol and only a very small proportion (1\%) formally screened for alcohol problems. Similarly, few officers indicated regularly offering brief advice (4\%) and/or referring patients to an appropriate drug and alcohol service (4\%). These findings are consistent with comparative research undertaken among staff in EDs, ${ }^{9}$ and may in part be explained by only $12 \%$ of officers in this study indicating moderate-tohigh levels of confidence in their ability to formally screen patients for alcohol use and alcohol problems and 32\% reporting confidence in referring patients. A lack of confidence has been commonly reported in other studies on $\mathrm{GPs}^{19}$ and ED staff, 9,20 and attributed to insufficient training in alcohol screening and referral. ${ }^{20}$ With $85 \%$ of officers reporting having received no training in the past year and $43 \%$ indicating no

Table 4: Actions that officers would be willing to undertake as part of their work.

\begin{tabular}{|c|c|c|c|}
\hline & \multicolumn{3}{|c|}{ Level of Willingness } \\
\hline & Nilling to... & Unsure & Not willing to... \\
\hline Ask patients whether they have been drinking alcohol. & $98 \%$ & - & $2 \%$ \\
\hline Ask patients about their quantity and frequency of alcohol. & $88 \%$ & $4 \%$ & $8 \%$ \\
\hline Screen patients for alcohol problems using a formal alcohol screening tool. & $42 \%$ & $26 \%$ & $32 \%$ \\
\hline Discuss and/or advise patients to change their drinking behaviour. & $47 \%$ & $21 \%$ & $32 \%$ \\
\hline Refer patients with alcohol problems to an appropriate drug and alcohol counselling service. & $68 \%$ & $14 \%$ & $18 \%$ \\
\hline Document and record assessment, intervention and referral on the Patient Health Care Record. & $90 \%$ & $5 \%$ & $5 \%$ \\
\hline $\begin{array}{l}\text { Provide patients with written information (e.g. hand them a card or pamphlet) on alcohol and local alcohol } \\
\text { treatments services. }\end{array}$ & $75 \%$ & $12 \%$ & $13 \%$ \\
\hline $\begin{array}{l}\text { Ask patients to provide the name of their usual GP and to sign an agreement so that I can send a report to } \\
\text { their GP about the incident and recommend follow-up with patients at their next GP visit. }\end{array}$ & $30 \%$ & $19 \%$ & $51 \%$ \\
\hline $\begin{array}{l}\text { Offer to make an appointment time for patients to discuss their drinking behaviour with an } \\
\text { appropriate counsellor or doctor. }\end{array}$ & $20 \%$ & $21 \%$ & $59 \%$ \\
\hline Ask patients for permission to send follow-up feedback and advice in the mail, tailored to individual patients. & $24 \%$ & $19 \%$ & $57 \%$ \\
\hline $\begin{array}{l}\text { Send a standard report to licensees (if relevant) and/or police to alert them that an alcohol-related incident } \\
\text { which I was required to attend, has occurred. }\end{array}$ & $33 \%$ & $20 \%$ & $47 \%$ \\
\hline $\begin{array}{l}\text { Talk to community groups (e.g. schools, workplaces, sporting groups, clubs etc) about alcohol and } \\
\text { safe drinking practices. }\end{array}$ & $52 \%$ & $14 \%$ & $34 \%$ \\
\hline Attend training programs on how to deliver screening and brief alcohol interventions myself. & $66 \%$ & $14 \%$ & $20 \%$ \\
\hline $\begin{array}{l}\text { Meet with GPs, Emergency Department staff and other health care workers to discuss and plan the } \\
\text { establishment of more effective referral networks. }\end{array}$ & $64 \%$ & $15 \%$ & $21 \%$ \\
\hline $\begin{array}{l}\text { Work with local police and other relevant agencies to assist in identifying and developing prevention } \\
\text { strategies for reducing alcohol-related harm in my local community. }\end{array}$ & $67 \%$ & $15 \%$ & $18 \%$ \\
\hline
\end{tabular}


training at all in the management of alcohol-affected patients, these results could be viewed as supportive of this association. Given a strong consensus among officers on the need for formal training on how to deal with, make referrals and offer brief advice for alcohol-affected patients, a lack of training may be acting as a barrier to optimal clinical practice. Also worth noting is the inability of ambulance officers to directly refer patients to drug and alcohol services at present, suggesting that opportunities and processes for referral to alternative care pathways be reviewed.

An alternative explanation to the reported low rates of screening and referrals may lie with the finding that only $34 \%$ of participants considered that screening for alcohol and offering brief advice to patients was part of their clinical responsibility as an ambulance officer. Other research on doctors and nurses ${ }^{9}$ has also indicated an ambiguity surrounding the perceived role of health care providers in relation to screening and referral for alcohol problems. What is not clear is whether this is due to a divergence in views around the demarcation of roles and clinical responsibilities of different health care providers or is more to do with the belief that screening and/or talking to patients about their alcohol use while they are under the influence of alcohol is inappropriate and likely to be ineffective as a way of managing alcohol-affected patients and reducing alcoholrelated harm. While the detection of alcohol use problems could be improved by formal screening of alcohol-affected patients by ambulance officers at the time of attendance at an incident, it would seem that brief counselling and referral would be more appropriate at a follow-up appointment. The findings presented in Table 4 indicated that a high proportion of officers would be willing to undertake these actions as part of their clinical responsibility. Most of the participants in this study were also in agreeance to providing 'at-risk' drinkers with written information (e.g. a pamphlet) on alcohol and local services and refer patients to an appropriate drug and alcohol counselling service. A willingness to carry out these actions suggests that many officers view their role as more than just delivering emergency health care and transporting patients to hospital. Health promotion is considered by many to be integral to the role of an ambulance officer.

Additionally, this study showed that officers are ready to undertake a number of other actions as part of alcoholharm reduction efforts. These included meeting with other health care providers to plan more effective referral systems, delivering talks to community groups, and working with other agencies to develop harm-reduction strategies. Initiatives such as the Ambulance Drug and Alcohol Program for Teenagers implemented by the Victorian Metropolitan Ambulance Service $^{21}$ could be expanded upon and disseminated to all ambulance services both across Australia and internationally.
Further training is needed to increase the knowledge and skill-base of officers to allow them to undertake alcohol-harm reduction strategies and future research should evaluate both the efficacy and effectiveness of a combination of actions.

There are a number of limitations to this study. First, only 53\% of the 500 invited officers participated in this study. However, this low response rate is comparable with other surveys of health care providers and the sample is proportionally representative of the four division sectors indicating that results are generalisable across New South Wales. Second, we were not able to validate perceived estimates of alcoholrelated call-outs with actual prevalence rates due to PCR forms not currently allowing for recording of such data and/or being incomplete, however estimates appear to be consistent with previous research conducted on both ambulance and ED hospital staff. Further research is needed to establish the reliability and validity of officers' self-report. Third, while many ambulance officers believed that their role could and should include additional health promoting and preventative actions, the views of their employers or senior staff were not included as part of this study. Their beliefs may be markedly different from ambulance staff due to conflicting priorities, in particular, the importance placed on competing responsibilities and the potential for any added roles to adversely affect ambulance mandated response times.

Despite these limitations, this study clearly shows the significant burden that alcohol and alcohol-related harms inflicts upon the work of ambulance officers and highlights the potential usefulness and insights that ambulance data could provide to improved surveillance and understanding of alcohol-related harm in the community. Ambulance officers are ideally situated to identify and detect 'at-risk' drinkers because of the apparent high prevalence of alcohol-related call-outs, and are willing to screen for problem drinking. There are a number of unrealised opportunities for expansion of the health promotion role of ambulance officers for which they appear willing to undertake and integrate into their responsibilities as a health care provider. Further exploration of the views of senior ambulance service personnel, together with assessment of the capacity and feasibility of embracing new roles appears justified. 


\section{References}

1. World Health Organization Secretariat. 61st World Health Assembly. Strategies to Reduce the Harmful Use of Alcohol [report]. Geneva (CHE): WHO; 2008 March 20. Report No.: A61/13.

2. Australian Transport Council. National Road Safety Action Plan 2003 and 2004 Canberra (AUST): Commonwealth Department of Transport and Regional Services; 2003.

3. World Health Organization. Diet, Nutrition and the Prevention of Chronic Diseases. Geneva (CHE): WHO; 1990. Report No.: Technical Report Series 797.

4. Grimm D. Staggering toward a global strategy on alcohol abuse. Science. 2008;320:862-3.

5. Ministerial Council on Drug Strategy. National Alcohol Strategy 2005 - 2009 [Consultation Paper]. Canberra (AUST): Australian Government Department of Health and Ageing; 2005.

6. Bertholet N, Daeppen JB, Wietlisbach V, Fleming M, Burnand B. Reduction in Alcohol Consumption by Brief Alcohol Intervention in Primary Care. Arch Intern Med. 2005;165:986-95.

7. Lock CA. Screening and brief alcohol intervention: What, why, who, where and when? A review of the literature. J Subst Use. 2004;9(2):91-101.

8. Moyer A, Finney J, Swearingen C, Vergun P. Brief interventions for alcohol problems: a meta-analytic review of controlled investigations in treatment seeking and non-treatment seeking populations. Addiction. 2002;97(3):279-92.

9. Indig D, Copeland J, Conigrave KM, Rotenko I. Attitudes and beliefs of emergency department staff regarding alcohol-related presentations. Int Emerg Nurs. 2009;17(1):23-30.

10. Nordqvist C, Johansson K, Bendtsen P. Routine screening for risky alcohol consumption at an emergency department using the AUDIT-C questionnaire. Drug Alcohol Depend. 2004;74:71-5.
11. Charalambous MP. Alcohol and the accident and emergency department: a current review. Alcohol Alcohol. 2002;37:307-12.

12. Roche AM, Watt K, McClure R, Purdie DM, Green D. Injury and alcohol: A hospital emergency department study. Drug Alcohol Rev. 2001(20):155-66.

13. Gillham K, Sidebottom C, Bowman J, Wiggers J, Nicholas C. Alcohol related ambulance attendances as an indicator of alcohol related harm in the community. Unpublished observation 2005.

14. Victorian Department of Health. Victoria's Alcohol Action Plan 2008-2013. Melbourne (AUST): Responsible Alcohol Victoria, Department of Justice; 2008.

15. London Ambulance Service [news on the Internet]. London (UK): National Health Services Trust; 2009 [cited 2009 Sept 3]. Alcohol-related Calls. Available from: http://www.londonambulance.nhs.uk/news/alcohol-related_calls.aspx

16. Bailey P. Ambulance Paramedics - An Endangered Species? Australasian Journal of Emergency Care. 1997;4(2):12-4.

17. Mann NC, Hedges JR. The role of prehospital care providers in the advancement of public health. Prehosp Emerg Care. 2002;6(2):S63-S7.

18. Tippett V, Clark M, Woods S, FitzGerald G. Towards a national research agenda for the ambulance and pre-hospital sector in Australia. Journal of Emergency Primary Health Care. 2003;1(1-2).

19. Deehan A, Marshall EJ, Strang J. Tackling alcohol misuse: opportunities and obstacles in primary care. Br J Cen Pract. 1998;48:1779-82.

20. D'Onofrio G, Nadel ES, Degutis LC, Sullivan LM, Casper K, Bernstein E, et al. Improving emergency medicine residents' approach to patients with alcohol problems: a controlled educational trial. Ann Emerg Med. 2002;40:50-62.

21. Metropolitan Ambulance Service. Secondary School Program. ADAPT, An Ambulance Drug and Alcohol Program for Teenager. Melbourne (AUST): Community Education and Development, Ambulance Victoria; 2008.

\section{Authors}

Marita Lynagh and Rob Sanson-Fisher, School of Medicine and Public Health, University of Newcastle, New South Wales Anthony Shakeshaft, National Drug and Alcohol Research Centre, University of New South Wales

\section{Correspondence}

Dr Marita Lynagh, School of Medicine and Public Health, Discipline of Health Behaviour Sciences, University of Newcastle, David Maddison Building, Callaghan New South Wales 2308. Fax: (02) 4913 8148; e-mail: Marita.Lynagh@newcastle.edu.au 
Reproduced with permission of the copyright owner. Further reproduction prohibited without permission. 